\title{
Recursos prosódicos usados na fala de apresentadores de telejornal - uma análise fonético-acústica comparativa
}

\author{
Gabriela Silveira Sóstenes ${ }^{1}$
}

Aldir Santos de Paula ${ }^{2}$

\section{Resumo}

O objetivo deste trabalho foi comparar dados fonético-acústicos e perceptivo-auditivos das narrações de fala de uma dupla de apresentadores de telejornal de uma mesma emissora de televisão, investigando as mudanças ocorridas em mais de vinte anos de carreira. Para o corpus da análise acústica e perceptivo-auditiva, foi escolbido um telejornal apresentado por essa dupla, no inicio da carreira, exibido nacionalmente nos anos 80. Esse mesmo telejornal foi regravado atualmente por esses mesmos apresentadores, simulando uma apresentação verdadeira. Os aspectos prosódicos avaliados foram: frequências (média, máxima e minima); intensidade (média) e duração dos segmentos vocálicos. A partir da análise dos dados, concluímos que ambos os sujeitos avaliados, apresentaram atualmente uma narração com mais naturalidade $e$ coloquialidade. As frequências médias, máximas e minimas foram os parâmetros prosódicos que mostraram mudanças mais significativas. Este trabalho representa uma contribuição relevante à linguistica, à fonoaudiologia e ao telejornalismo, na medida em que contribui para uma maior compreensão da evolução dos aspectos comunicativos envolvidos na linguagem de telejornalistas brasileiros.

Palavras-chave: Telejornalismo. Prosódia. Fonética. Análise acústica. Linguística

\footnotetext{
${ }^{1}$ Universidade de Ciências da Saúde de Alagoas.

${ }^{2}$ Universidade Federal de Alagoas.
} 


\section{Introdução}

Nos primórdios da televisão brasileira, o telejornalismo era uma espécie de leitura televisionada de notícias da imprensa. Os apresentadores de telejornal possivelmente não tinham consciência de que os recursos prosódicos da fala e os recursos não verbais (os movimentos corporais, os gestos, as expressões faciais) ajudavam na compreensão da mensagem transmitida. Esses apresentadores possuíam, geralmente, vozes graves e impostadas, quase ausência de gestos e expressões faciais, conferindo à linguagem qualidade nada coloquial.

Mattos (2002) conta que a história da TV reflete as fases de desenvolvimento e as políticas oficiais adotadas pelo governo. Unindo fala e história, observamos que as locuções dos primeiros telejornais refletem uma grande influência radiofônica, o modelo norte-americano de televisão e, não podemos também deixar de considerar, a influência da censura no Brasil que acompanhou os jornalistas por vinte e um anos.

Cotes (2008) descreve que através da história podemos tentar explicar o formalismo de antes, a artificialidade da linguagem e da forma de narrar. Filho (2002) relata que no início do telejornalismo a preocupação era transmitir credibilidade, passando a notícia sem demonstrar afetividade.

Hoje sabemos que cada assunto de telejornal deve despertar uma atitude em quem fala e em quem ouve. A voz usada e o corpo precisam ter relação com o conteúdo transmitido.

Por observar essa evolução do telejornalismo brasileiro ao longo das últimas décadas é que houve o interesse em realizar este trabalho. O objetivo foi comparar dados fonético-acústicos e perceptivo-auditivos das narrações de fala de uma dupla de apresentadores de telejornal, de uma mesma emissora de televisão, tidos como referência no telejornalismo brasileiro, investigando as mudanças ocorridas em mais de vinte anos de carreira.

\section{Aspectos teórico-metodológicos}

Nosso objeto de estudo foi baseado em um telejornal exibido nacionalmente em outubro de 1989, ano em que esses dois apresentadores iniciaram juntos a apresentação. Esse mesmo telejornal foi regravado em outubro de 2011, em áudio e vídeo, pelos mesmos apresentadores, na bancada do telejornal, simulando uma apresentação ao vivo. 
Os aspectos prosódicos avaliados na fala dos apresentadores foram: frequências média, máxima e mínima, intensidade e duração dos segmentos vocálicos.

Para a coleta do material, foi solicitado inicialmente autorização da Direção Globo de Jornalismo e Esporte. Em seguida, autorização dos sujeitos selecionados, com assinatura do Termo de Consentimento Livre e Esclarecido - TCLE, além da colaboração da fonoaudióloga da emissora da qual os sujeitos pesquisados fazem parte.

Os informantes responderam um questionário que traçou o perfil social e vocal (sexo, idade, tempo e trajetória profissional, nacionalidade e naturalidade do informante, se teve ou tem intervenção fonoaudiológica, se tem ou teve alterações vocais ou laríngeas).

Estas informações são importantes porque fazem diferença nos achados pesquisados sexo, idade, tempo de atuação profissional, se teve ou tem intervenção fonoaudiológica ou se tem ou teve patologias vocais alteram, por exemplo, valores de frequência fundamental. A experiência profissional e o treino sistemático de exercícios de voz aprimoram a comunicação global. Se os apresentadores apresentam alterações vocais e/ou laríngeas, funcionais ou secundárias a patologias laríngeas, podem alterar também parâmetros de intensidade vocal e duração dos segmentos vocálicos.

Para preservar suas identidades, os apresentadores foram identificados da seguinte forma: Apresentador 1 e Apresentador 2 e possuem os seguintes perfis (quadros 1 e 2):

Apresentador 1

Sexo masculino, 48 anos de idade em 2011 (data da última gravação), nascido em São Paulo. Jornalista, apresentador de telejornal desde 1985 e desde 1986 é apresentador de telejornais na mesma emissora pesquisada. Desde 1996 é apresentador do mesmo telejornal. Tem assessoria fonoaudiológica desde o início da carreira.

Quadro 1: perfil do Apresentador 1. 
Apresentador 2

Sexo feminino, 49 anos de idade em 2011, nascida no Rio de Janeiro. Jornalista, apresentadora de telejornal desde 1987. Em julho de 1989, começou a dividir a bancada de um telejornal ao lado do Apresentador 1. Em 1993, saiu da apresentação deste telejornal e assumiu a apresentação de outro programa telejornalístico. De 1998 até final de 2011 apresentou um telejornal ao lado do Apresentador 1. Tem assessoria fonoaudiológica desde o início da carreira.

\section{Quadro 2: perfil do Apresentador 2.}

Essas análises foram feitas por meio do programa Praat (www.praat.com). Selecionamos para análise dois enunciados emitidos por cada apresentador (duas cabeças de matéria - texto lido pelo apresentador no estúdio para chamar a reportagem, contendo as informações mais relevantes que serão exibidas na matéria, segundo BISTANE e BACELLAR, 2005).

Os aspectos prosódicos avaliados foram: frequências (média, máxima e mínima); intensidade (média) e duração.

\section{Análise e descrição dos dados}

A seguir serão expostos os resultados do apresentador 1 e posteriormente do apresentador 2 .

\section{Dados fonético-acústicos e preceptivo-auditivo das narrações do apresentador 1}

As tabelas 1 e 2 mostram os dados comparativos do perfil social e vocal e dos dados fonético-acústicos e perceptivo-auditivos das narrações do apresentador 1. 


\begin{tabular}{ccccc}
\hline Apresentador 1 & Idade & $\begin{array}{c}\text { Atuação } \\
\text { profissional }\end{array}$ & Fonoaudiologia & Problemas vocais \\
\hline 1989 & 26 anos & 4 anos & Sim, desde & Não \\
2011 & 48 anos & 26 anos & o início da carreira & \\
\hline
\end{tabular}

Tabela 1: perfil social e vocal do apresentador 1.

A tabela 2 mostra a comparação dos dados prosódicos de frequências e intensidade utilizados na narração do Apresentador 1:

\begin{tabular}{|c|c|c|c|c|c|}
\hline Apresentador 1 & $\begin{array}{l}\text { Frequência } \\
\text { média }\end{array}$ & $\begin{array}{l}\text { Frequência } \\
\text { Máxima }\end{array}$ & $\begin{array}{l}\text { Frequência } \\
\text { mínima }\end{array}$ & $\begin{array}{l}\text { Gama } \\
\text { tonal }\end{array}$ & Intensidade \\
\hline 1989 & $143 \mathrm{~Hz}$ & $204 \mathrm{~Hz}$ & $91 \mathrm{~Hz}$ & $113 \mathrm{~Hz}$ & $60 \mathrm{~dB}$ \\
\hline 2011 & $118 \mathrm{~Hz}$ & $197 \mathrm{~Hz}$ & $51 \mathrm{~Hz}$ & $146 \mathrm{~Hz}$ & $63 \mathrm{~dB}$ \\
\hline
\end{tabular}

Tabela 2: frequências média, máxima e mínima - gama tonal - intensidade de todas as vogais dos enunciados falados pelo apresentador 1 .

O Apresentador 1, em 2011, teve uma diminuição dos valores de frequências média, máxima e mínima comparados com a narração de 1989. Diminuiu $25 \mathrm{~Hz}$ (ver tabela 2). A gama tonal foi mais extensa que o ano de 1989, $33 \mathrm{~Hz}$. No ano de 1989, o apresentador usava uma tessitura mais reduzida, com pouca variação melódica, conferindo uma curva melódica mais linear, nivelada. Em 2011, o apresentador usa entoações com maiores variações de graves e agudos em toda a elocução, porém com menor amplitude da curva entoacional em 2011. Em 1989, observamos maior amplitude da curva melódica, maiores subidas e descidas da frequência vocal (figuras 1 e 2 do Praat e 3 do gráfico de frequência).

As figuras 1 e 2 do programa Praat mostram análise da curva entoacional dos anos de 1989 e 2011 e o oscilograma: 


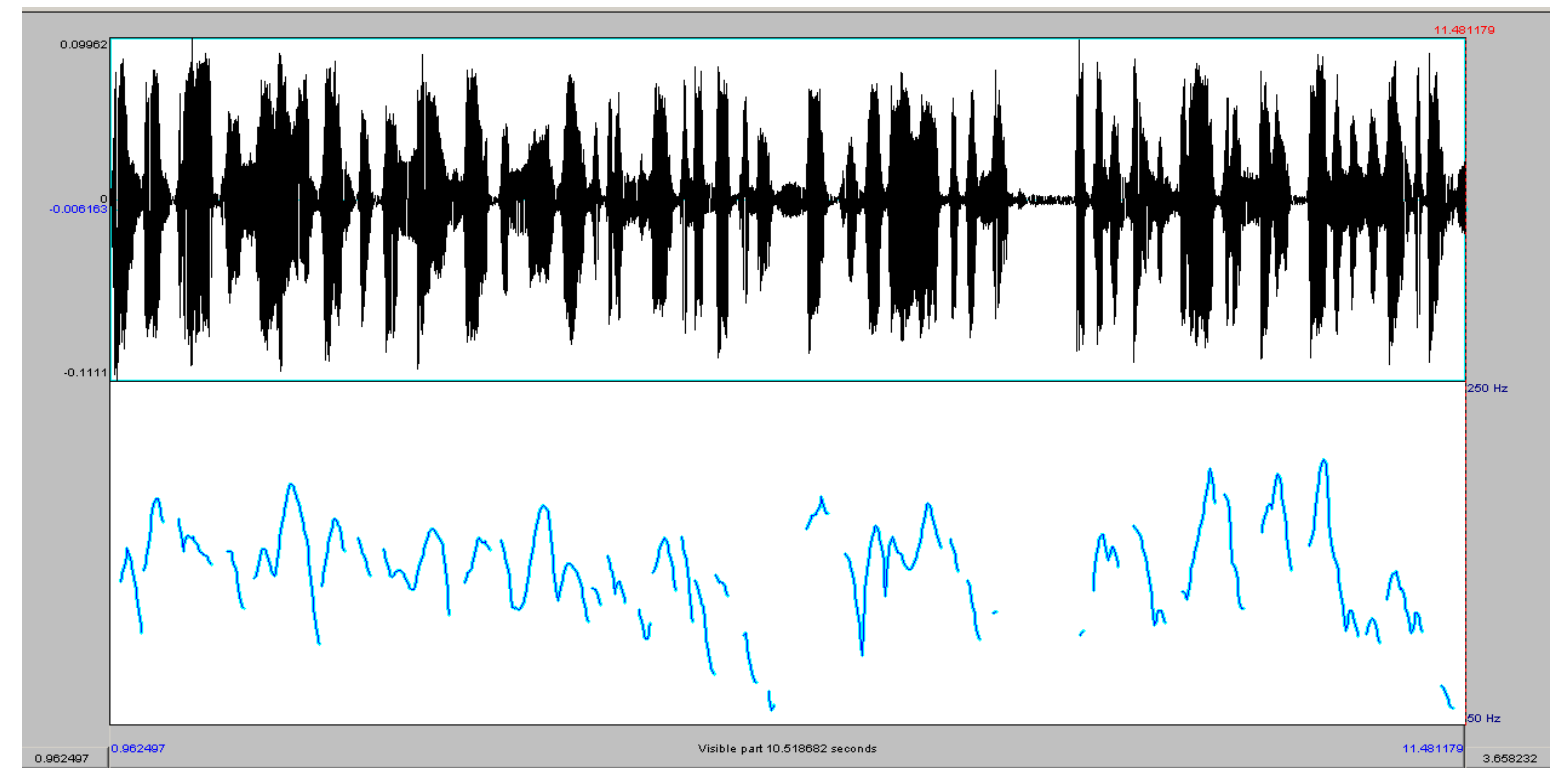

Figura 1: narração do Apresentador 1 - ano de 1989.

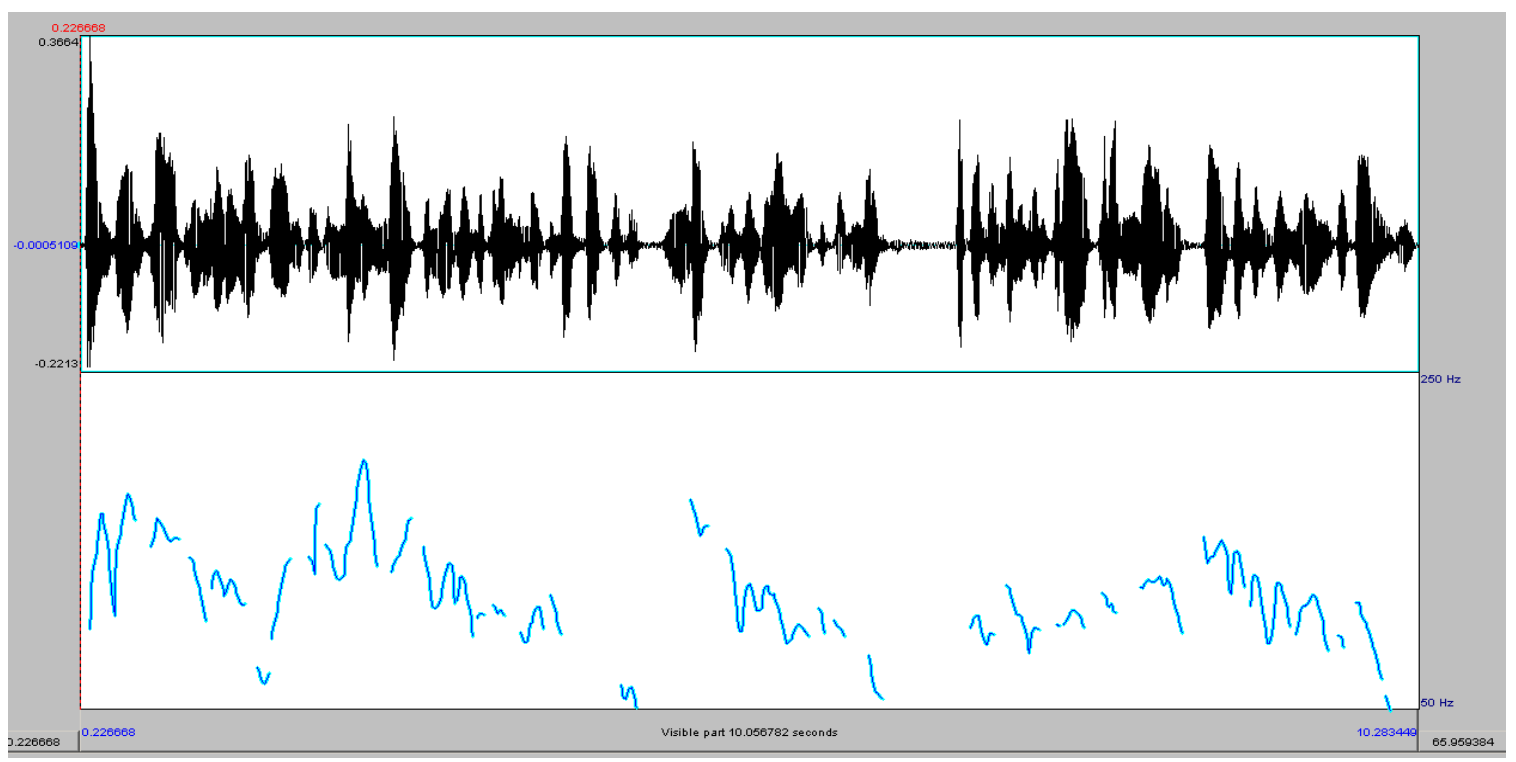

Figura 2: narração do Apresentador 1 - ano de 2011.

A redução na frequência ao longo dos anos no Apresentador 1 pode ser explicada por uma redução natural da frequência fundamental com a idade (valores masculinos: de 20 a 29 anos, aproximadamente $120 \mathrm{~Hz}$; entre 40 e 49 anos, aproximadamente $107 \mathrm{~Hz}$, segundo HOLLIEN e SHIPP, 1972). Cruttenden (1986) descreve que a média dos falantes masculinos é aproximadamente $120 \mathrm{~Hz}$.

Apresentadores de telejornal preferem vozes graves para conferir credibilidade, tão importante no jornalismo. E exercícios de voz/fala passados pelo fonoaudiólogo para aquecimento vocal podem visar o abaixamento ou elevação do pitch, ganho da extensão fonatória, 
estabilidade, firmeza, resistência vocal (BEHLAU, 2005), além de melhorias no uso dos recursos prosódicos da narração e dos recursos não verbais. Os telejornalistas da Rede Globo são acompanhados frequentemente por fonoaudiólogos. O Apresentador 1 teve acompanhamento com fonoaudiólogo desde o início da carreira.

Aumentar a frequência e intensidade da voz no uso profissional da comunicação é comum, como pode ser visto nas pesquisas de Gama (2003), Sóstenes (2005) e Sóstenes e Souto (2003). O telejornalista projeta mais a voz com intuito de ser mais compreendido e passar formalidade. Só que isso atualmente está mudando; podemos observar a narração do Apresentador 1 no ano de 2011, cuja frequência encontra-se na média dos falantes masculinos, como estabelece Cruttenden (1986). Hoje quanto mais próximo da naturalidade, coloquialidade, melhor, pois este aspecto aproxima mais o telespectador.

Nascimento e Sóstenes (2012) compararam o parâmetro prosódico frequência na voz de quatro apresentadores de telejornal, do sexo masculino, em épocas distintas das carreiras, por meio de análise fonético-acústica e perceptivo-auditiva. Os apresentadores que iniciaram a carreira na década de 70 apresentaram em comum o aumento das frequências médias nos últimos anos da análise, tornando a voz mais próxima da coloquial, menos impostada, menos restrita nos tons graves, características dos apresentadores-locutores que migraram do rádio para o telejornalismo. Os apresentadores que iniciaram nas décadas de 80-90, apresentaram redução das frequências médias nos últimos anos das análises, tornando a voz também mais natural, menos impostada.

Os resultados da pesquisa de Nascimento e Sóstenes (2012) foram semelhantes aos achados no Apresentador 1; as frequências foram mais elevadas e a gama tonal mais restrita na primeira avaliação em 1989, e em 2011 tornou-se mais grave, mais coloquial. O Apresentador 1 chegou em uma fase em que já existiam "modelos" de apresentadores de telejornal aceitos pelo público; esses apresentadores, mesmo vindo do rádio, já não utilizavam vozes tão impostadas e graves como no início das carreiras, devido a vários fatores, tais como: adaptações ao novo meio de comunicação - televisão, inovações tecnológicas, mudanças políticas - abrandamento da censura militar, mudanças de comportamento da população.

Cotes (2008) observou que, na década de 80, os apresentadores mostraram maior faixa na extensão de F0, direcionamento de pitch mais abrupto e maior ocorrência de pitch accents. 
Abaixo, figura com gráfico das médias das frequências vocálicas das narrações dos anos de 1989 e 2011 do Apresentador 1:

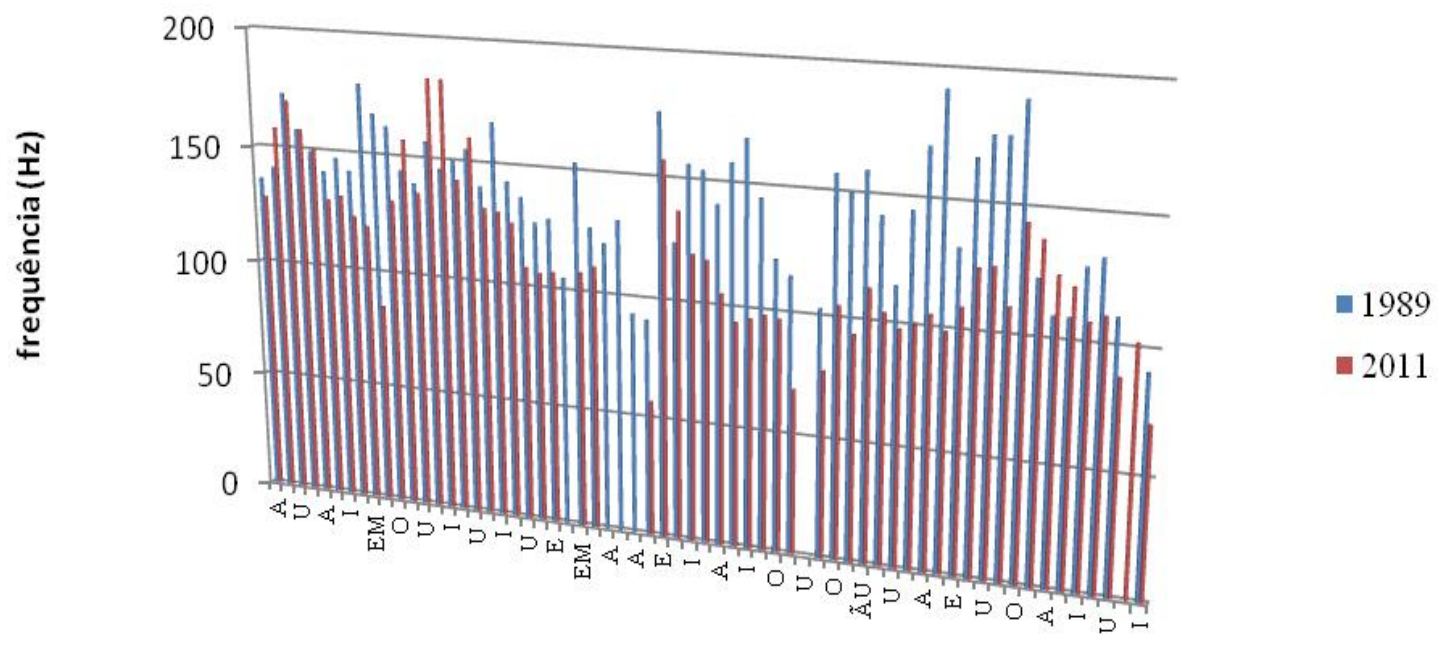

Figura 3: comparação das frequências médias das narrações de 1989 e 2011 do Apresentador 1.

O tempo de duração das vogais diminuiu no ano de 2011 comparado com o ano de 1989, conforme a figura 3, que mostra o gráfico de duração das vogais dos enunciados. O apresentador, além de elevar a frequência da voz para impostar, também usava o recurso do alongamento das vogais de uma forma não natural para enfatizar. Autores como Crystal (1969), Pike (1945), Moraes (1993) e Massini-Cagliari (1992) afirmam que a duração é um aspecto que salienta, põe em evidência alguma característica do enunciado, marcando sua proeminência, e descrevem que a sílaba acentuada é sempre a mais longa do enunciado, o que faz com que a duração seja um dos correlatos acústicos para o acento em português. O ideal é usar esse recurso espontaneamente, sem forçar o alongamento.

A figura 4 mostra um gráfico comparativo dos anos de 1989 e 2011 dos valores em segundos da duração da pronúncia dos segmentos vocálicos. Em 2011, houve uma diminuição da duração dos segmentos vocálicos na narração: 


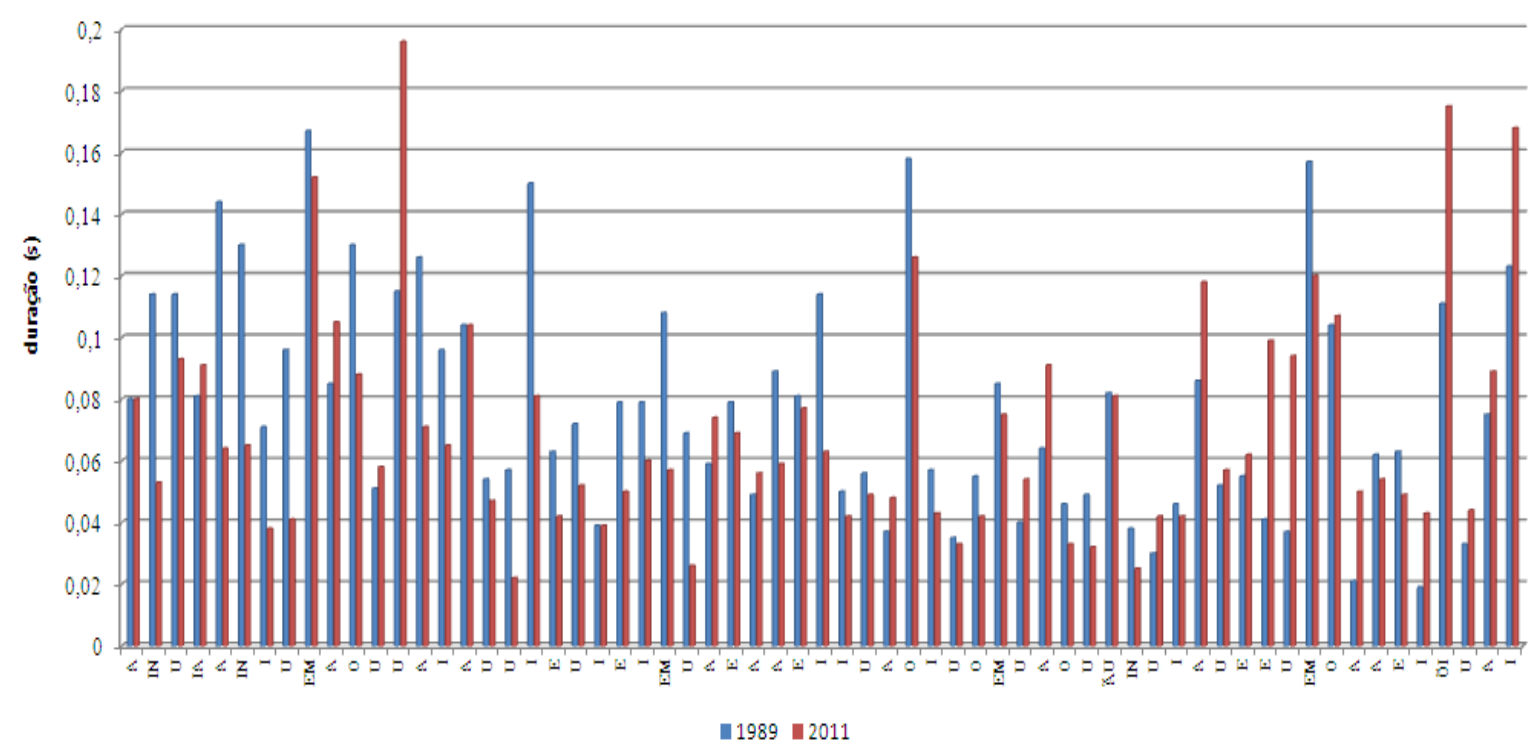

Figura 4: valores de duração das vogais das narrações de 1989 e 2011 do Apresentador 1.

Já a intensidade aumentou apenas $3 \mathrm{~dB}$ na média; talvez tenha sido a amplificação sonora de 2011 com melhor qualidade de áudio. A figura 5 mostra o gráfico com os valores de intensidade de ambos os anos.

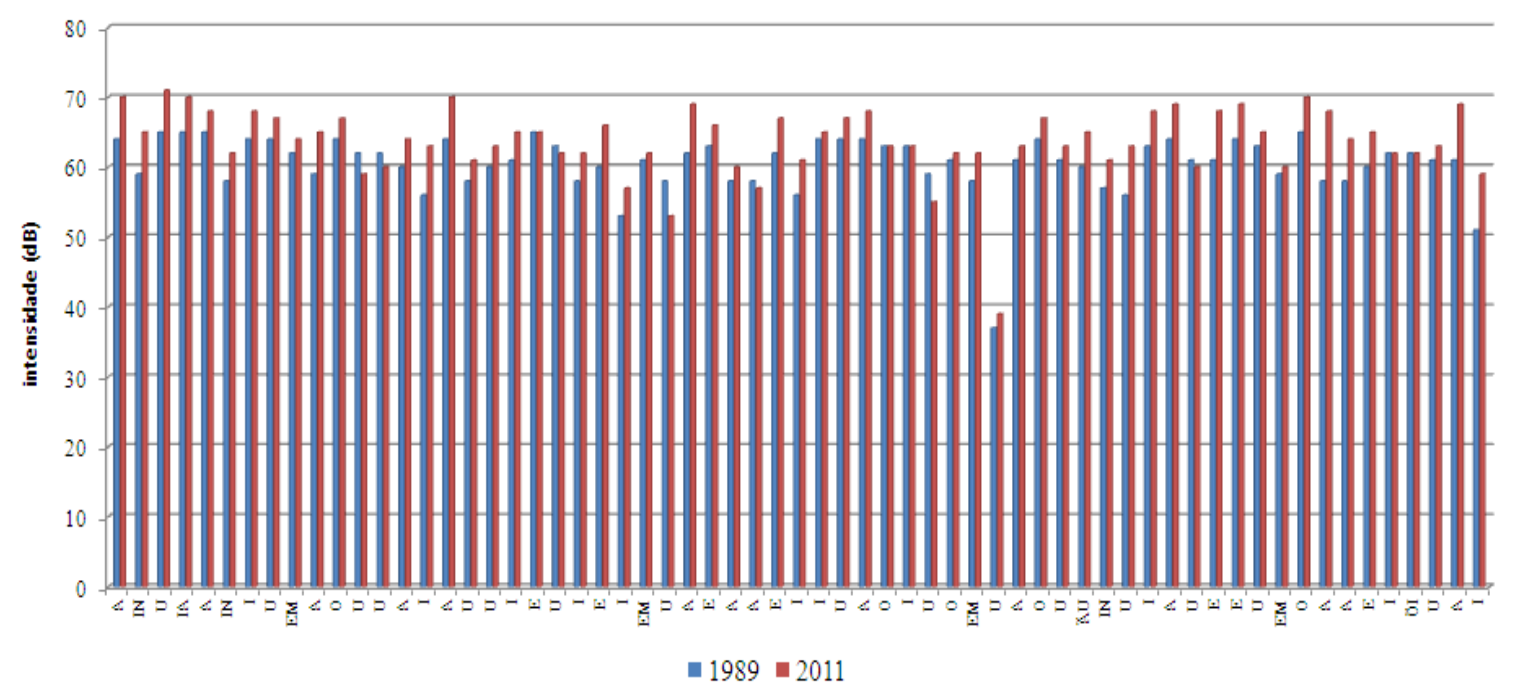

Figura 5: valores da intensidade média das vogais das narrações de 1989 e 2011 do Apresentador 1.

\section{Dados fonético-acústicos e preceptivo-auditivo das narrações do apresentador 2}

As tabelas 3 e 4 mostram os dados comparativos do perfil social-vocal e dos dados fonético-acústicos e perceptivo-auditivo das narrações do Apresentador 2. 


\begin{tabular}{ccccc} 
Apresentador 2 & Idade & $\begin{array}{c}\text { Atuação } \\
\text { profissional }\end{array}$ & Fonoaudiologia & Problemas vocais \\
\hline 1989 & 27 anos & 2 anos & Sim, desde & Não \\
2011 & 49 anos & 24 anos & o início da carreira & \\
\hline
\end{tabular}

Tabela 3: perfil social-vocal do Apresentador 2.

\begin{tabular}{lccccc}
\hline Apresentador 2 & $\begin{array}{c}\text { Frequência } \\
\text { média }\end{array}$ & $\begin{array}{c}\text { Frequência } \\
\text { máxima }\end{array}$ & $\begin{array}{c}\text { Frequência } \\
\text { mínima }\end{array}$ & $\begin{array}{c}\text { Gama } \\
\text { tonal }\end{array}$ & \begin{tabular}{c} 
Intensidade média \\
\hline 1989
\end{tabular} \\
$246 \mathrm{~Hz}$ & $428 \mathrm{~Hz}$ & $126 \mathrm{~Hz}$ & $302 \mathrm{~Hz}$ & $61 \mathrm{~dB}$ \\
2011 & $198 \mathrm{~Hz}$ & $449 \mathrm{~Hz}$ & $119 \mathrm{~Hz}$ & $330 \mathrm{~Hz}$ & $64 \mathrm{~dB}$ \\
\hline
\end{tabular}

Tabela 4: média das frequências média, máxima e mínima - gama tonal - intensidade de todas as vogais dos enunciados falados do apresentador 2.

O apresentador 2 em 2011 também teve, assim como o Apresentador 1, uma diminuição dos valores de frequências comparados com a narração de 1989. Diminuiu $48 \mathrm{~Hz}$ da frequência média (ver os dados na tabela 4). Provavelmente pelos mesmos fatores que já foram mencionados anteriormente na fala do Apresentador 1. A gama tonal em 2011 também foi mais extensa que a do ano de 1989, 28 Hz. Em 1989, o apresentador narra com frequências mais altas e apresenta quedas abruptas destas frequências. Em 2011, o apresentador usa entoações de fala coloquial, com menor amplitude da curva entoacional, semelhante ao Apresentador 1 (figuras 6 e 7 do Praat e 8 do gráfico de frequência).

As figuras 6 e 7 mostram as análises acústicas das emissões dos anos de 1989 e 2011 do apresentador 2. O ano de 2011 apresenta uma queda da frequência da voz e uma menor amplitude da curva entoacional. Em 2011, o apresentador 2 continua a elevar a frequência e intensidade no início dos enunciados. 


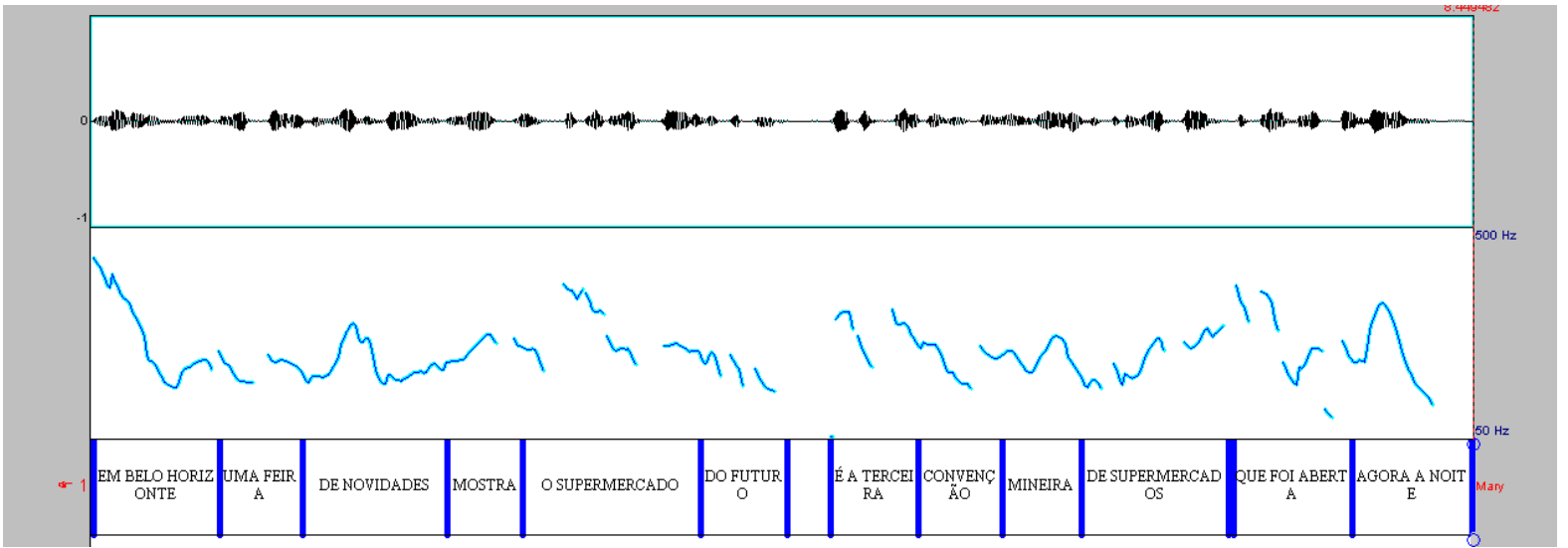

Figura 6: narração do ano de 1989 - Apresentador 2.

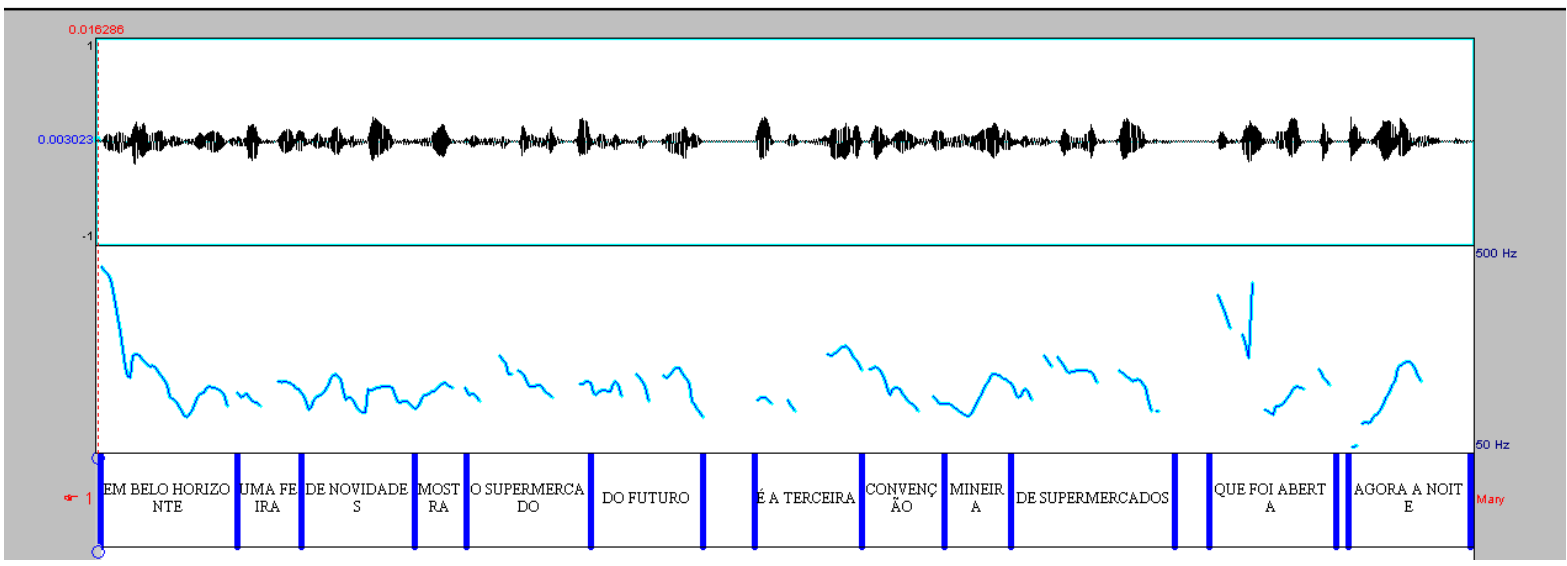

Figura 7: narração do ano de 2011 - Apresentador 2.

A figura 8 mostra também gráfico comparativo das frequências médias dos segmentos vocálicos analisados em 1989 e 2011:

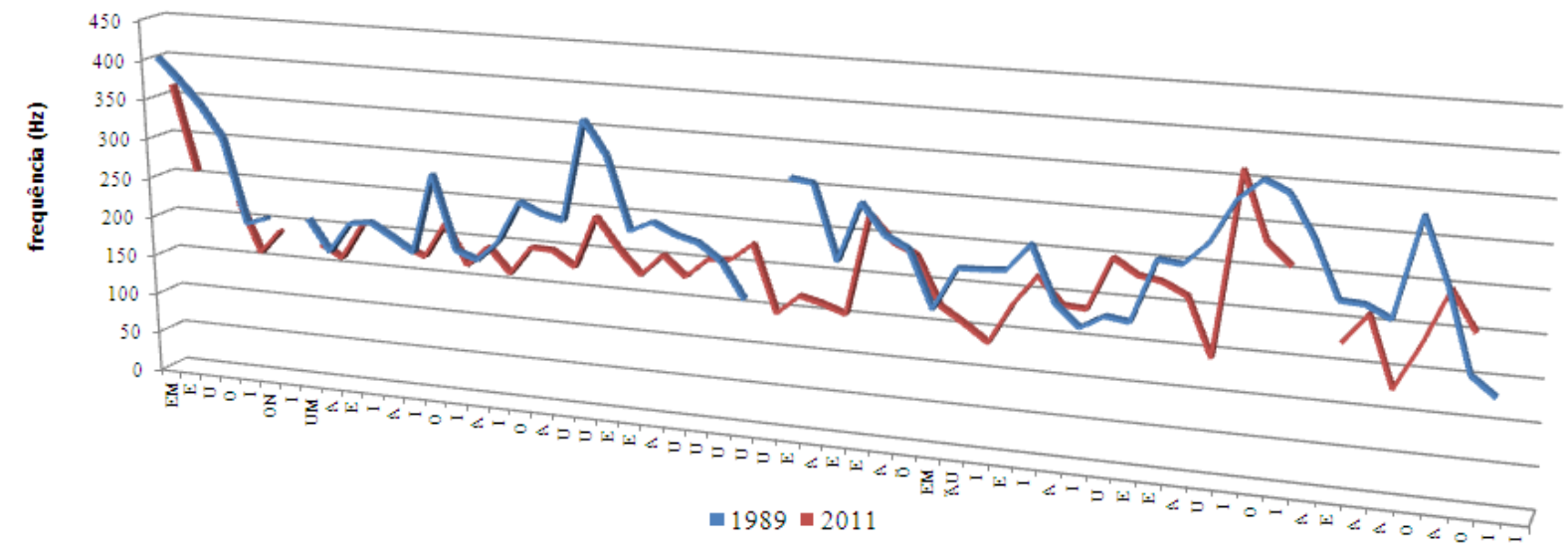

Figura 8: frequências médias utilizadas na narração do apresentador 2 nos anos de 1989 e 2011. 
Cruttenden (1986) descreveu que a média da frequência das mulheres é $225 \mathrm{~Hz}$. Kelley (1977) descreve que mulheres na faixa de 20 a 29 anos apresentam valores médios de frequência habitual ao redor de $227 \mathrm{~Hz}$; na faixa de 40 a 49, $214 \mathrm{~Hz}$; e na faixa de 80 a 89 anos, $197 \mathrm{~Hz}$. O apresentador no ano de 1989 apresentava uma frequência acima da média descrita pelos autores (246 Hz) e em 2011 apresentou abaixo da média (198 Hz), mesmo para sua faixa etária atual, 49 anos de idade.

Stier e Neto (2003) relatam que repórteres do sexo feminino em início de carreira tendem a apresentar pitch agudo e intensidade fraca. Apresentam diferenças de voz e de narração em relação às mais experientes. A pouca idade e a falta de experiência podem dar leveza excessiva na narração. O apresentador 2 tinha, no ano de 1989, 27 anos de idade e dois anos de atuação como apresentadora de telejornal. Feijó (2003) refere que, apesar de não haver nenhum rigor com relação ao uso do pitch na comunicação do telejornalista, em geral, homens e mulheres desejam apresentar vozes mais graves para passar credibilidade, segurança.

Gama (2003) avaliou a frequência fundamental de telejornalistas. Os valores médios de frequência para as mulheres foram de $193 \mathrm{~Hz}$ e, para os homens, $118 \mathrm{~Hz}$. Ocorreu presença de maior modulação, ênfases, intensidade, pausas e prolongamentos de vogais nas emissões profissionais. Os apresentadores deste estudo apresentaram no ano de 2011 frequências semelhantes aos achados desta autora.

Uma característica encontrada no apresentador 2, comum na fala de mulheres, é iniciar frases com frequências mais altas e intensidade elevada e à medida que o final da frase se aproxima há uma queda, tanto na frequência como na intensidade. Essa variação de frequência e intensidade diminuiu na narração atual.

No treinamento de voz para profissionais da comunicação, os exercícios específicos para aquecimento vocal promovem uma modificação de parâmetros de voz, como frequência fundamental e intensidade. Alguns exercícios vocais promovem modificações imediatas e a longo prazo na qualidade da emissão (RAMIG; VERDOLINI, 1998). Os jornalistas que participaram desta pesquisa têm assessoria fonoaudiológica desde o início da profissão. Depoimento da jornalista Fátima Bernardes no livro "Fonoaudiologia e Telejornalismo":

Ué! Você faz fono? Mas você não trabalha na televisão? Já não fala tudo certo? Eu já perdi a conta do número de vezes que tive que responder a esta pergunta. A grande maioria das pessoas acha que a ida a um fonoaudiólogo só se justifica se você tem um problema de linguagem para corrigir [...]. No meu caso, todos os encontros foram e são muito proveitosos [...]. A importância de fazer um 
bom aquecimento vocal [...]. O fono pode nos ajudar a manter a qualidade e a saúde de nossa voz. Mas isso não é tudo [...]. Muitas vezes, a reportagem está correta, mas a forma de apresentá-la, ou seja, a leitura, a aparição do profissional no vídeo deixam a desejar. Nesta hora o trabalho da fonoaudiologia pode ajudar muito (BERNARDES, 2003).

Stier e Feijó (2005) compararam as vozes de 13 telejornalistas antes e depois do aquecimento vocal imediato e após a repetição diária por um período de quatro semanas. Observaram quais as modificações ocorridas nesse período, a fim de avaliar a eficácia da preparação diária da voz desses profissionais. Os resultados apontaram que o aquecimento vocal proporcionou uma melhor qualidade vocal, modificação da frequência fundamental e aumento do número de harmônicos em quase todos os indivíduos pesquisados.

O aquecimento vocal é de suma importância para preparar as pregas vocais para o uso vocal intenso, pois flexibiliza esta musculatura, possibilita o adequado fechamento das pregas vocais e diminui o fluxo aéreo transglótico, evitando eventuais lesões (SCARPEL; PINHO, 2001).

A duração das vogais no ano de 2011 diminuiu e a intensidade média também aumentou 3 dB na narração do apresentador 2 (figuras 9 e 10). O apresentador, no ano de 2011, na primeira frase narrada, fez um processo de elisão nas palavras "Belo Horizonte" ([belorizõtsi]), suprimindo o primeiro "o" de "Horizonte", e monotongou a palavra "feira", suprimindo a vogal “i”; já em 1989, pronunciou todos os fones destas palavras. Na segunda frase narrada de 1989, o apresentador utilizou o processo de elisão nas palavras "agora a noite", suprimindo a terceira vogal "a" ([agperanojtsi]); em 2011 não realizou este processo. Foram três processos de supressão de vogal em 2011 e dois em 1989, contribuindo também para a diminuição do tempo total de elocução em 2011. Esses processos são utilizados com frequência na fala coloquial, espontânea.

Gráfico comparativo dos valores de duração dos segmentos vocálicos dos anos de 1989 e 2011 do Apresentador 2: 


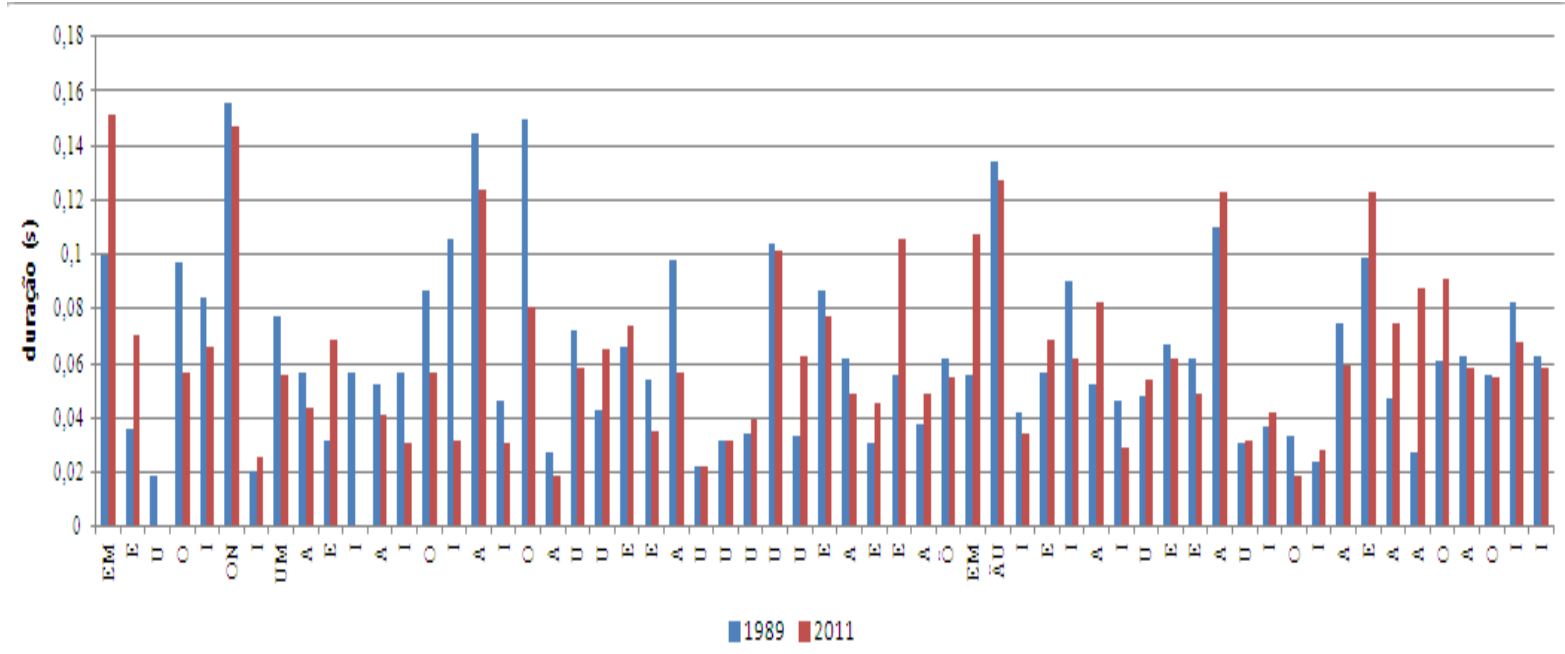

Figura 9: duração das vogais utilizadas nas narrações do apresentador 2.

Gráfico comparativo dos valores da intensidade utilizados nas narrações de 1989 e 2011 do Apresentador 2:

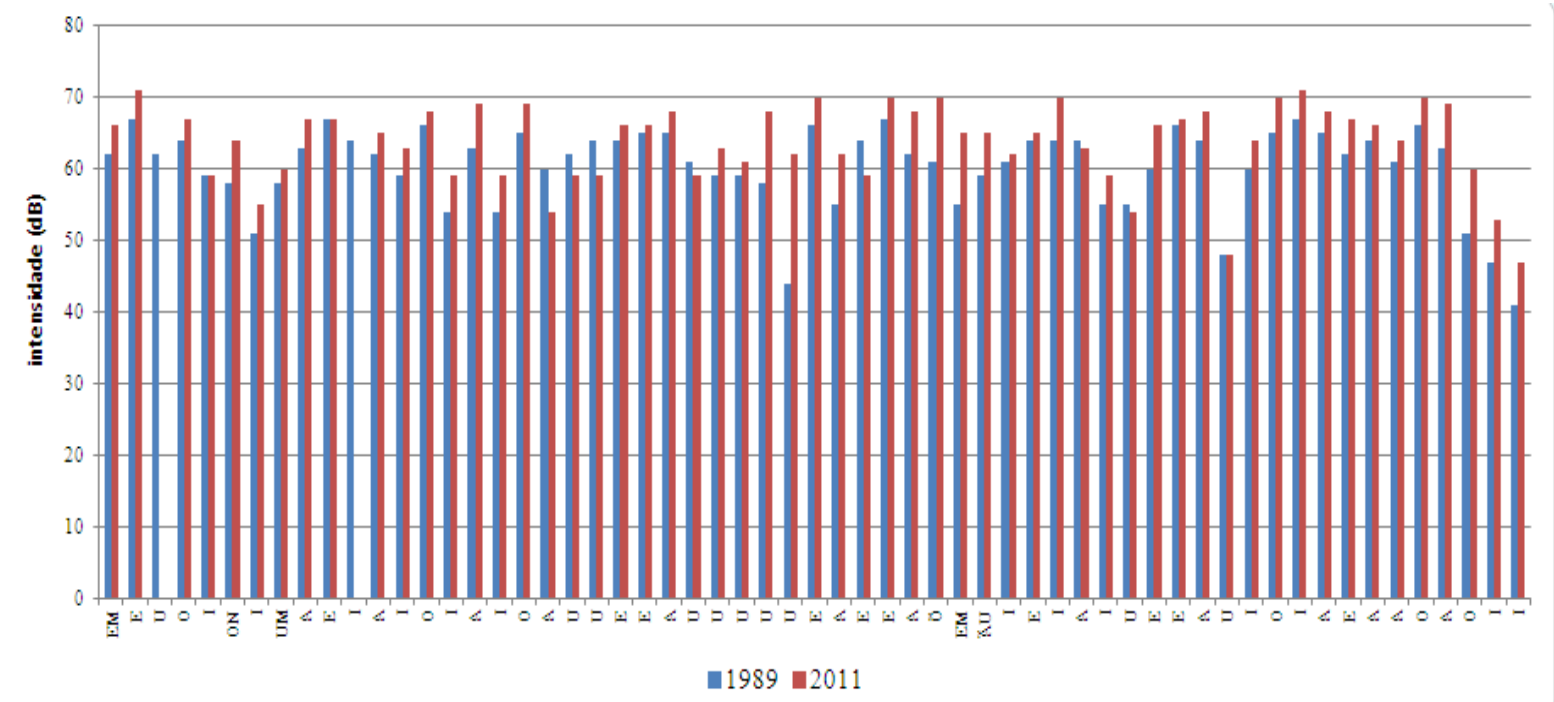

Figura 10: médias das intensidades utilizadas nas narrações do Apresentador 2.

Em relação à apresentação geral do telejornal de 1989, os planos de filmagem eram fechados em cada apresentador e não havia interatividade entre os dois apresentadores, mesmo quando o plano de filmagem era aberto para os dois. Havia ausência de gestos manuais, rigidez corporal e muito pouca expressividade facial dos apresentadores.

$\mathrm{Na}$ regravação de 2011, observamos câmeras com movimentos e enquadramentos dinâmicos. Nos planos de filmagens abertos, existiu interatividade entre os apresentadores, troca 
de olhares, presença constante de gestos manuais, expressões faciais e movimentação corporal, mesmo sendo com um texto de 22 anos atrás.

Os apresentadores, antes de regravarem o material, questionaram o porquê de ter sido escolhido um telejornal da década de 1980, já que o objetivo do trabalho era comparar a evolução da linguagem. Falaram: "não se escreve mais desse jeito", "fica difícil ler de uma maneira espontânea", "não retrata o momento do telejornalismo".

Foi explicado que, para se comparar precisamente dados de prosódia de fala, o mais indicado é que a análise seja com o mesmo enunciado e pronunciado pelo mesmo indivíduo falante. A voz e a fala são como uma impressão digital - carregam características próprias que distinguem os indivíduos entre si. O mesmo enunciado de fala mostra as mesmas características morfossintáticas, fonológicas e semânticas, por isso a análise fica mais precisa.

\section{Conclusão}

A linguagem atual dos telejornalistas é mais interativa e informal. Observamos mudanças no uso dos recursos prosódicos de fala estudados.

O Apresentador 1 mostrou uma redução das frequências da voz no ano de 2011, aproximando-se da média dos falantes masculinos.

Apesar da redução das frequências, o Apresentador 1 usou uma gama tonal mais extensa, com maior variação de tons graves e agudos. Em 2011 também a amplitude da curva entoacional diminuiu, deixando a narração telejornalística mais coloquial.

O tempo de duração dos segmentos vocálicos diminuiu no ano de 2011, já a intensidade aumentou. Em 1989, o Apresentador 1 utilizou intensidade média de 60 dB na narração, e em 2011, 63 dB.

O Apresentador 2 também diminuiu a frequência da voz na narração de 2011 e aumentou a gama tonal. Essa diminuição da frequência da voz de ambos os apresentadores pode ser explicada por fatores como: idade, experiência profissional e acompanhamento fonoaudiológico com prática de exercícios de voz desde o início da carreira. 
O Apresentador 2 em 1989 narrava com frequências mais elevadas e apresentava quedas abruptas destas frequências. Em 2011, a amplitude da curva entoacional diminuiu.

Em 2011, o Apresentador 2 prolongou menos os segmentos vocálicos, aumentou a intensidade em $3 \mathrm{~dB}$ e utilizou três processos de supressão de vogais na emissão do enunciado, enquanto que no ano de 1989 foram dois processos.

Constatamos em ambos os apresentadores estudados uma narração de fala com mais naturalidade e coloquialidade. As frequências médias, máximas e mínimas foram os parâmetros prosódicos que mostraram mudanças mais significativas em termos perceptuais e acústicos.

No quadro 3 descrevemos as semelhanças dos dados fonético-acústicos e perceptivoauditivos encontrados no ano de 2011 de ambos os apresentadores estudados:

\begin{tabular}{|c|}
\hline Apresentadores 1 e 2 - Narração prosódica atual \\
\hline Frequência média mais grave \\
\hline Gama tonal mais extensa \\
\hline Aumento da intensidade vocal \\
\hline Diminuição da duração dos segmentos vocálicos \\
\hline Diminuição da amplitude da curva entoacional \\
\hline
\end{tabular}

Quadro 3: dados prosódicos fonético-acústicos e perceptivo-auditivos semelhantes encontrados na narração dos Apresentadores 1 e 2.

Hoje os telejornais estão mais "conversados". É comum vermos apresentadores conversando espontaneamente entre si, com repórteres e entrevistados improvisando fala, fazendo comentários; interagindo nas passagens com as pessoas e com o ambiente.

Os telejornais atuais mostram uma maior liberdade e espontaneidade no uso dessas estratégias comunicativas. Os enquadramentos e movimentos das câmeras, a qualidade da imagem, o cenário, as vestimentas também contribuem para a melhora dos aspectos da comunicação como um todo.

\section{Referências}

BEHLAU, M. et al. Voz profissional: aspectos gerais e atuação fonoaudiológica. In: BEHLAU, M. Voz: o livro do especialista. Rio de Janeiro: Revinter, 2005. 
BERNARDES, F. Depoimento. In: KYRILLOS, L.; FEIJÓ, D. (Org.). Fonoaudiologia e telejornalismo: baseado no III Encontro Nacional de Fonoaudiologia da CGJ. Rio de Janeiro: Revinter, 2003.

BISTANE, L.; BACELLAR, L. Jornalismo de TV. São Paulo: Contexto, 2005.

COTES, C. O estudo dos gestos vocais e corporais no telejornalismo brasileiro. Tese (Doutorado em Linguística Aplicada e Estudos da Linguagem). São Paulo: Pontifícia Universidade Católica, 2008.

CRUTTENDEN, A. Intonation. Cambridge: Cambridge University Press, 1986.

CRYSTAL, D. Prosodic systems and intonation in English. Cambridge: The Cambridge University, 1969.

CRYSTAL, D. Dicionário de linguística e fonética. Rio de Janeiro: Jorge Zahar Ed., 2000.

FEIJÓ, D. Avaliando a comunicação oral. In: KYRILLOS, L. R. (Org.). Fonoaudiologia e telejornalismo - relatos de experiências na Rede Globo de Televisão. Rio de Janeiro: Revinter, 2003.

FILHO, C. M. A saga dos cães perdidos. Comunicação e Jornalismo. 2 ed. São Paulo: Hacker, 2002.

GAMA, A. C. Caracterização do padrão de emissão espontânea e profissional no telejornalismo. In: KYRILLOS, L. R. (Org.). Fonoaudiologia e telejornalismo - relatos de experiências na Rede Globo de Televisão. Rio de Janeiro: Revinter, 2003.

HOLLIEN, H.; SHIPP, T. Speaking fundamental frequency and chronologic age in males. J. Speech Hear. Res., 15, 1972, p. 155-159.

KELLEY, A. Fundamental frequency measurements of female voices from twenty to ninety years of age (unpublished manuscript). Greensboro: University of North Carolina, 1977.

MASSINI-CAGLIARI, G. Acento e ritmo. São Paulo: Contexto, 1992.

MATTOS, S. História da televisão brasileira. 2 ed. Petrópolis: Vozes, 2002.

MORAES, J. A entonação modal brasileira: fonética e fonologia. Caderno de estudos Linguísticos, Campinas, v. 25, 1993, p. 101-111.

NASCIMENTO, R. R.; SÓSTENES, G. Análise comparativa dos aspectos prosódicos da narração de telejornalistas. Anais do XX Congresso Brasileiro de Fonoaudiologia. Brasília DF, 2012.

PIKE, K. L. The intonation of American English. Ann Arbor: The Michigan University Press, 1945.

RAMIG, L.; VERDOLINI, K. Treatment efficacy: voice disorders. J Speech Lang Hear Res., 141, 1998, p. 101-116. 
SCARPEL, R. D.; PINHO, S. M. R. Aquecimento e desaquecimento vocal. In: PINHO, S. M. R. Tópicos em voz. Rio de Janeiro: Guanabara Koogan, 2001.

SÓSTENES, G.; SOUTO, M. A. C. Narração de um grupo de telejornalistas - análise pré e pósatuação fonoaudiológica. In: KYRILLOS, L.; FEIJÓ, D. (Org.). Fonoaudiologia e telejornalismo: baseado no III Encontro Nacional de Fonoaudiologia da CGJ. Rio de Janeiro: Revinter, 2003.

SÓSTENES, G. Estilo de narração de telejornalistas esportivos. In: KYRILLOS, L.; FEIJÓ, D.; GAMA, A. C. C. (Org.). Fonoaudiologia e telejornalismo: baseado no IV Encontro Nacional de Fonoaudiologia da CGJ. Rio de Janeiro: Revinter, 2005.

STIER, M. A.; FEIJÓ, D. Aquecimento vocal para telejornalista. In: GAMA, A. C.; KYRILLOS, L.; FEIJÓ, D. Fonoaudiologia e telejornalismo - relatos do IV Encontro Nacional de Fonoaudiologia da CGJ. Rio de Janeiro: Revinter, 2005.

STIER, M. A.; NETO, B. C. Oficina de narração. In: KYRILLOS, L. R. (Org.). Fonoaudiologia e telejornalismo - relatos de experiências na Rede Globo de Televisão. Rio de Janeiro: Revinter, 2003. 


\section{Abstract}

This study aims to compare acoustic-phonetic and perceptible hearing data from speech narrations of two newscasters from the same TV channel, investigating the development through more than 20 years of career. A newscast shown nationally in the 80 's was chosen as corpus for acoustic and perceptual hearing analysis. This was the year that these TV News presenters began to share the bench in this newscast. This same newscast was rewritten by these same presenters in 2011, simulating a true presentation. Prosodic aspects evaluated were: frequencies (average, maximum and minimum); intensity (average) and vocalic segments duration. From the data analysis, we conclude that both subjects evaluated show more natural and colloquial narration nowadays. The average, maximum and minimum frequencies were the prosodic parameters that showed the most significant changes. This paper represents an important contribution to linguistics, speech therapy and TV newscast, in the way that it contributes to a greater understanding of the evolution of the aspects involved in the Brazilian newscasters' communicative language.

Keywords: TV journalism. Prosody. Phonetics. Acoustic analysis. Linguistics 